\title{
Leviathan and the Soft Animal: Medical Humanism and the Invertebrate Models for Higher Nervous Functions, 1950s-90s
}

\author{
FABIO DE SIO*
}

\begin{abstract}
Keywords: History of Neuroscience; Model Animals; Octopus; Medical Humanism
\end{abstract}

Sometime between the late 1960s and the early 1970s, a 'Monsieur Jourdain syndrome' seems to have spread among basic researchers and clinicians in fields as diverse as neurology, psychology, psychiatry, behavioural studies, physiology, biochemistry and pharmacology. Almost overnight, they realised that they were but neuroscientists. ${ }^{1}$

This novel conscience was soon translated into concern for the specificity and historical origins of the new science, with remarkably convergent results. A few main features recurred as central to the definition of the field: the importance of technological advances; the role of modelling practices in the bridging of gaps between unrelated perspectives; the intrinsic interdisciplinary and variously reductionistic nature of the field. Most important, however, seemed to be not so much what the new multidiscipline actually was, or had been, but what it was to become: nothing less than the cornerstone of a general unified science to come, one attacking 'the ultimate goal of all science and philosophy - how does the mind/brain work!'

To some extent, the recent historiography of the neurosciences seems to have taken the bulk of those claims at face value, especially as regards the concern for an appropriation of the question of human nature, behaviour and values, indeed of 'what it means to be human'. 3

(C) Fabio De Sio, 2011.

* Fabio De Sio, Research Fellow, School of History, Queen Mary, University of London, temporary address: 6th floor, Wellcome Building, 183 Euston Road, London NW1 2BE, UK. Email: fabiodesio@gmail.com

\footnotetext{
${ }^{1}$ See, for instance, the earnest admission of J.Z. Young, 'Sources of Discovery in Neuroscience', in F. Worden, J.P. Swazey, and G. Adelman (eds), The Neurosciences: Paths of Discovery (Cambridge, MA: MIT Press, 1975), 15-46: 40.

${ }^{2}$ See Stanley Finger, Origins of Neuroscience: A History of Explorations into Brain Function (Oxford: Oxford University Press, 2001); George Adelman, 'The Neurosciences Research Program at MIT and the Beginning of the Modern Field of Neuroscience', Journal of the History of the Neurosciences: Basic and Clinical Perspectives, 19, 1 (2010), 15-23. See also Francis O. Schmitt, 'Preface' to Gardner C.
}

Quarton, Theodore Melnechuk and Francis O. Schmitt, The Neurosciences: A Study Program (New York: Rockefeller University Press, 1967). On a critical note, see Carl F. Craver, 'The Making of a Memory Mechanism', Journal of the History of Biology, 36, 1 (2003), 153-95; and especially Max Stadler, 'The Neuromance of Cerebral History', in Surparna Choudhury and Jan Slaby (eds), Critical Neuroscience: Between Lifeworld and Laboratory (Hoboken, NJ: Wiley-Blackwell, forthcoming).

${ }^{3}$ Cf. Pietro Corsi, The Enchanted Loom: Chapters in the History of Neuroscience (Oxford: Oxford University Press, 1991); Joelle M. Abi-Rached and Nikolas Rose, 'The Birth of the Neuromolecular Gaze', History of the Human Sciences, 23, 1 (2010), 1-26; Roger Smith, Being Human: Historical Knowledge and the Creation of Human Nature (New York: Columbia University Press, 2007), a meaningful attempt to cope with the last question. 


\section{Fabio De Sio}

Legitimate as they are, these pictures of the neurosciences failed to tackle the historiographic issue itself: the validity and extent of 'the neurosciences' as a meaningful historical/analytical category. Quite tellingly, one could say, they have failed to draw the proper philosophical distinction between 'substance' and 'contingency' in the phenomenon.

The following, instead, is an attempt at approaching 'the neurosciences' as a contingent disciplinary and, later, historiographical umbrella-definition, which at once houses and shadows a number of relatively autonomous if historically related sets of issues, practices and models. This might in turn help questioning the present general concept of the neurosciences, their extension, their cultural and ideological bearing, perhaps their epistemological hierarchy. To this end, I will use the cheap trick of inverting the focus of the grand narrative, taking the vantage point from an animal, instead of from the science, or the object, to exchange the contingent and the substantial.

The story I will sketch here is that of an improbable laboratory animal, Octopus vulgaris, of how it came to cross paths with the nascent neurosciences and almost to become a symbol of the novel approach, a model of the brain, incorporating many of the major features and instances of the neuroscientific philosophy (search for simplified models, focus on universal mechanisms and anthropocentric orientation). I thus wish to open a window on the variety of, and often contradiction among, numerous disciplinary and epistemic trajectories that were later to merge into the neurosciences.

\section{The Evolution of a 'Marine Guinea Pig'}

A very familiar animal for those in the Mediterranean, ${ }^{4}$ the octopus is much less so in northern Europe and Great Britain. Nordic mythology, fishermen tales and, later, the accounts of travelling naturalists conveyed a sense of disquiet in relation to this charming, but also voracious and aggressive, animal. ${ }^{5}$

It took the second half of the nineteenth century, and the foundation of the first public aquaria, for a rehabilitation of the octopus in the eyes of the mid-European and British public. The first octopuses shown captive in England, in the mid-1800s, soon became attractions, eliciting sympathetic curiosity for their camouflage skills and elegant postures and movements, hitting the headlines of local newspapers, and being sincerely mourned at death. ${ }^{6}$ It is indeed in aquaria that the mental powers of the octopus were brought to public attention, prompting a first metamorphosis of the animal from a scary monster into a wonder animal.

It wasn't only children and grandparents who sanctified the transmutation. New marine stations equipped for the maintenance of living animals afforded naturalists the chance of accessing the octopus in an environment close to its natural one, to study its anatomy and physiology, and to gain a limited but direct acquaintance with its life in the sea.

${ }^{4}$ See D'Arcy W. Thompson, 'How to Catch Cuttlefish', The Classical Review, 42, 1 (1928), 14-18.

${ }^{5}$ Henry Lee, Aquarium Notes: The Octopus or the 'Devil-Fish' of Fiction and of Fact (London:

Chapman and Hall, 1875).

\author{
${ }^{6}$ Frank W. Lane, Kingdom of the Octopus: \\ The Life History of the Cephalopoda (London: \\ Jarrolds, 1957).
}




\section{Leviathan and the Soft Animal}

Zoologists and physiologists were the first to appreciate the octopus as an experimental object: its anatomical convergences with the vertebrates, great resilience to the insults of surgery, the absence of bleeding during operation, and the ease to reach every inner organ made it popular as a 'marine guinea pig'. ${ }^{7}$ On the other hand, the early Darwinian apostles in the field of psychology - students of animal mind, and observers of animal will - were as well exposed to, and duly impressed by, the charms and behavioural variability of the cephalopod, making it object of methodical observation and experimentation. ${ }^{8}$

It was the juxtaposition of these two opposing ways of looking at the octopus that paved the way for a further metamorphosis, from aquatic guinea pig to an ideal neurological model. The double essence of a simple animal with a complex behaviour, of an invertebrate with a vertebrate behaviour is exactly what appealed to the zoologist John Zachary Young, when, working in the marine Zoological Station of Naples in the late 1930s, he conceived his own ambitious approach to the exploration of learning and memory mechanisms.

Learning, Young surmised, cannot be accounted for in terms of simple neural chains or stimulus-response schemata: it belongs to the level of the 'whole animal'. Given the complexity of the phenomenon and our relative ignorance of the underlying machinery, only comparison with structures simpler than the vertebrate type could offer concrete hopes of progress. ${ }^{9}$ Once defined what learning, as a function of adaptation, meant to animals at various phylogenetic levels, one could hope that the comparison of the different structures involved in the same process would help to reach an acceptable standard definition of both the phenomenon and the mechanism. Thanks to its virtues, natural and experimental, the octopus was chosen as the first step of a comparative project, encompassing other cephalopods, insects and eventually, mammals.

It took two years of intense work (1947-9) for Young and his assistant Brian Blundell Boycott to attune the experimental system to their aims; indeed, to define what those very aims were. The labour was divided between the Naples Station - for behavioural experiments, based on shape discrimination and conditioning - and Young's Institute in London - for functional anatomy of the brain and definition of the putative 'memory store' in the brain. The first full report of the experiments, 'A Memory System in Octopus vulgaris Lamarck', appeared only in 1955, eight years after the start, but it was full of promise. ${ }^{10}$ The title itself spoke for the ambitiousness of the results. For the first time, the term 'system' was used in relation to memory formation, pointing to well-defined machinery, a network of individual, if connected, elements in the brain performing a

\footnotetext{
${ }^{7}$ G. Grimpe, 'Pflege, Behandlung und Zucht der Cephalopoden für zoologische und physiologische Zwecke', in E. Abderhalden (Hrg.) Handbuch der biologischen Arbeitsmethoden (Berlin: Urban \& Schwarzenberg, 1928), 331-402: 332.

${ }^{8}$ J.A. Bierens de Haan, Animal Psychology: Its Nature and its Problems (London: Hutchinson, 1949), 119; F.J.J. Buytendijk, 'Das Verhalten von Octopus nach teilweiser Zerstörung des "Gehirns", Archives
}

\author{
Néerlandaises de Physiologie de l'Homme et des \\ Animaux, 18 (1933), 24-65 . \\ ${ }^{9}$ B.B. Boycott and J.Z. Young, 'The Comparative \\ Study of Learning', in J. F. Danielli and R. Brown (eds), \\ The Comparative Study of Learning (Cambridge: \\ Cambridge University Press, 1950), 432-53: 432-4. \\ ${ }^{10}$ B.B. Boycott and J.Z. Young, 'A Memory \\ System in Octopus vulgaris Lamarck', Proceedings of \\ the Royal Society, B, 143 (1955), 449-80.
}




\section{Fabio De Sio}

specific memory function, just like the digestive system performs digestion. ${ }^{11}$ The network had been stained and was shown, anatomically and indisputably to be composed of 're-entrant circuits' connecting the cerebral lobes. ${ }^{12}$ To the trained eye, the structure implied the function. ${ }^{13}$

Within a decade, the octopus system had been refined to such a level of productivity (on both the behavioural and the anatomical side) as to obliterate the original comparative project. In the second part of the 1950s, as more and more new acolytes joined the octopologist club, opening up new avenues of behavioural experimentation, Young concentrated on the anatomical side, on the networks and, especially, on the language employed in their description. The very concept of 'memory' in the animal underwent dramatic semantic shifts. Whereas in the early 1950s articles, the term 'memory' was used in a phenomenological sense, as a lasting change in behaviour pointing to a putative plastic change in the brain, ${ }^{14}$ by the $1960 \mathrm{~s}$, it acquired a different order of reality, becoming a physical part of the brain, 'much like the memory of which engineers speak'. ${ }^{15}$ Detailed histological work led to a specification of the 're-entrant circuits' in the brain in terms of the different cellular types involved, if with some acceptable dose of guessing. ${ }^{16}$ Finally, the cellular architecture and the behavioural repertoire of the simple animal were put in direct relation in a last, most-refined model of the octopus brain: the mnemon, or memory cell, in which the innate behaviour of the animal was reduced to attack and retreat, and rooted into the anatomical connections of different cell types in the memory lobes. Much as it was (admittedly) tentative and rough, the mnemon offered a plausible, general model, a behavioural/anatomical learning unit: it told at least 'what to look for, and where'. ${ }^{17}$ From an epistemic thing, Young turned the octopus memory system into a candidate technical object - a model for the brain in general.

The shaping of the model was meaningfully paralleled by a reorientation of the research effort from a planned comparison of learning phenomena (which had never actually started, despite Young's reiterated promises to his sponsors) to a deep investigation of learning structures, involving electron microscopy, intracellular recording and the building of electronic analogues. ${ }^{18}$ His construction of the octopus model, in terms not merely of animals and descriptions, but also of theoretical framework and available equipment, appealed to different epistemic communities throughout the $1950 \mathrm{~s}$ and 1960s. Again, the picture of a simple animal with a complex behaviour proved an essential element of the octopus' fortune as a candidate model system. Biophysicists, physiologists, psychologists and zoologists alike, as well as charities and the US Air Force,

\footnotetext{
${ }^{11}$ R.L. Buckner, 'Memory Systems: An Incentive, Not an End Point', in Henry L. Roediger, Yadin Dudai and Susan M. Fitzpatrick (eds), Science of Memory: Concepts (Oxford: Oxford University Press, 2007), 359-64.

${ }_{12}^{12}$ Boycott and Young, op. cit. (note 10).

${ }^{13}$ J.Z. Young, unpublished autobiographical sketch (1992). I thank Dr Antony Boycott for sharing the typescript with me.

${ }^{14}$ Boycott and Young, op. cit. (note 9); J.Z. Young, 'Growth and Plasticity in the Nervous
}

System: Ferrier Lecture, Delivered on June 28th, 1950', Proceedings of the Royal Society, B, 139 (1951), 18-37; Boycott and Young, op. cit. (note 10).

${ }^{15}$ J.Z. Young, 'Learning and Discrimination in the Octopus', Biological Reviews, 36 (1961), 32-96: 33-4.

${ }^{16}$ J.Z. Young, A Model of the Brain (Oxford: Clarendon Press, 1964).

${ }^{17}$ J.Z. Young, The Memory System of the Brain (Oxford: Oxford University Press, 1966), 7.

${ }^{18}$ Young, op. cit. (note 16), 299-323. 


\section{Leviathan and the Soft Animal}

came under the spell of the simple model, putting the Naples Station back on the map of international biology.

In this crowding are probably also to be found the reasons of the decline of Young's octopod model for the brain. Whereas, in the earliest phase of the work, the job was mastered and controlled by a limited and organised community, sharing a system of relations and loyalties as well as a vocabulary, a set of problems and instruments developed with time and experience, the inclusion of 'external' players jeopardised the simple model at all levels, from the management of the resources to the adequacy of the protocols, of the descriptions, of the assumptions. The re-entrant circuits, so seductively clear in the Nissl stains of the brain slices, were never proven to physiologically behave as such, and this because, to the desperation of the most refined electrode experts, the octopus and its brain just did not allow for the implant to work, as the more complicated invertebrates did. ${ }^{19}$ At a different level, and despite the great effort at refining both the instrumentation and the procedures, the behavioural side of the model was increasingly criticised as simplistic, and its value as a viable mechanical-anatomical model for 'learning' questioned.

As one of the main critics of the octopus model, Geoff Bittermann, said in 1960, 'As a working hypothesis, the proposition that learning is the same in all animals led to the study of many animals. As an article of faith. . . to concentration on one. ${ }^{20}$ Nevertheless, the octopus model of learning mechanisms survived the wave of criticism of the mid1960s. The way in which this happened is meaningful. The octopus as an actual experimental system - as conceived by Young and Boycott in the late 1940s - underwent a long eclipse after Young's retirement and, despite some attempts at reviving it in the early 1980s, was never resumed at the same level of complexity and ambition.

What remained, and proved very influential indeed, was the octopus model, the set of insights, guiding hypotheses and rhetoric devices that had been developed in the previous decades. The issue of simplification, of 'simple systems', for instance, had emerged in the 1960s as the key frontier of the study of brains and behaviours, and one requiring the mobilisation of cohorts of experts (zoologists, comparative anatomists, comparative psychologists) not usually associated with the common notion of 'the neurosciences'. Still, the cross fertilisation of different fields is only part of the story. The other part speaks of, at times, widely diverging perspectives and agendas competing on the same ground, if at different levels - epistemic, economic, symbolic - with inevitably resulting epistemological hierarchies. A cursory consideration of the outcomes of the Decade of the Brain should suffice to convince us of how the medically oriented, anthropocentric agenda of today's neuroscience has obliterated its multifaceted and varied origins. As the comparative neurologist Theodore H. Bullock put it in the 1980s: 'Neuroscience is part of biology, more specifically of zoology, and it suffers tunnel vision unless continuous with ethology, ecology, and evolution. ${ }^{21}$ This plea, from a major actor in the definition of 'the neurosciences' qua academic discipline, can be seen as an epitome of our story of a temporary model of the brain: a story of the coalescence of diverging and,

${ }^{19}$ B.B. Boycott, et al., 'Octopus Optic Responses', Experimental Neurology, 12, 3 (1965), 247-56.

${ }^{20}$ M.E. Bittermann, 'Toward a Comparative

${ }^{21}$ T.H. Bullock, 'Comparative Neuroscience Holds Promise for Quiet Revolutions', Science, 225, 4661 (1984), 473-8: 474.

Psychology of Learning', American Psychologist, 15, 11 (1960), 704-12: 705. 


\section{Fabio De Sio}

at times, incompatible traditions of temporary alliances to attack a foggy and vaguely defined problem. A shift of the historical gaze from the Leviathan-discipline of the Leviathan-brain to the many, variable monads - experimental systems, research programmes, animals, politics - that are at once single parts and unique representations of the monstre-science called 'the neurosciences' would probably reconcile us with the (trivially, intrinsically) contingent dimension of the 'ultimate science' and of its unique, incomparable object - and would help us focus our attention on more concrete and fundamental, if less evident and spectacular, underlying processes and cultural battlegrounds.

\section{Acknowledgement}

The author wishes to thank the Wellcome Trust for supporting his research. 